\title{
ARTERIO-VENOUS SHUNT IN THE CAVERNOUS SINUS WITH CONTRALATERAL OCULAR SIGNS*
}

\author{
BY \\ M. V. GRAHAM \\ Department of Ophthalmology, Cardiff Royal Infirmary
}

AN arterio-venous fistula between the internal carotid artery and the cavernous sinus may occasionally present with contralateral signs. Only two other cases have been recorded in which the diagnosis has been confirmed by arteriography (Jefferson, 1952; Ramos and Mount, 1953). Two further cases, not verified by arteriography, have been reported by Walsh (1957) and Dandy and Follis (1941). The last of these cases was confirmed at post mortem. Ramos and Mount made no attempt to account for the contralaterality of signs. The following example presents some interesting problems.

\section{Case Report}

A married woman, aged 64 years was knocked down by a lorry in January, 1962, but was not rendered unconscious. Skull $x$ rays the same day showed no fracture, and she was sent home from a near-by hospital. The same evening she complained of nausea and vomiting and returned to hospital where she stayed for one week.

Shortly after the accident she became aware of persistent head noises, but was not much troubled by these, being partially deaf.

3 months later, however, she complained of intermittent diplopia which after a few days became constant, and was worse on looking to the left. She was referred to the ophthalmic department at Cardiff Royal Infirmary where I saw her in July, 1962.

Examination.-Visual acuity-right and left $6 / 9+2$ unaided.

The right eye was normal in all respects. Intra-ocular pressure $20 \mathrm{~mm} . \mathrm{Hg}$; ocular movements full; fundi normal.

The left eye showed slight fullness of the left lower eyelid (Fig. 1), with $2 \mathrm{~mm}$. proptosis. Slight pulsation of the globe was evident on close inspection, and the lower bulbar conjunctiva showed moderate chemosis. There was defective abduction, but other ocular movements were normal. Intra-ocular pressure $28 \mathrm{~mm}$. Hg.

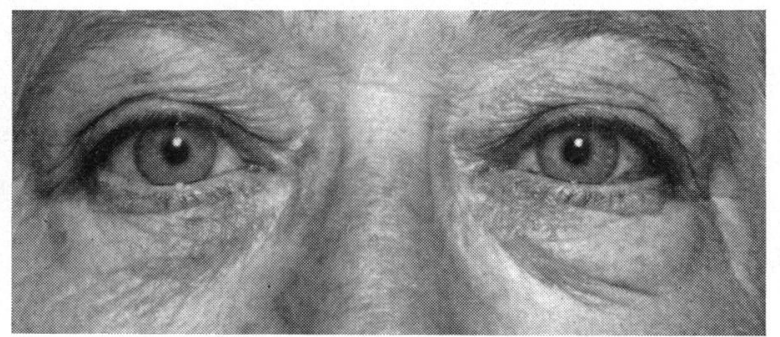

Fig. 1.-Oedema of left lower lid with left conjunctival injection.

* Received for publication June 16, 1965. 
Both visual fields were full. A bruit was heard all over the skull, being more marked over the right eye.

The Hess screen showed a slight left external rectus paresis. A provisional diagnosis of arteriovenous communication, probably of the left cavernous sinus, was made, and she was admitted for arteriography and neurosurgical opinion.

A left carotid angiogram was normal (Fig. 2), but a right carotid angiogram showed arteriovenous shunt of the cavernous sinus (Fig. 3).

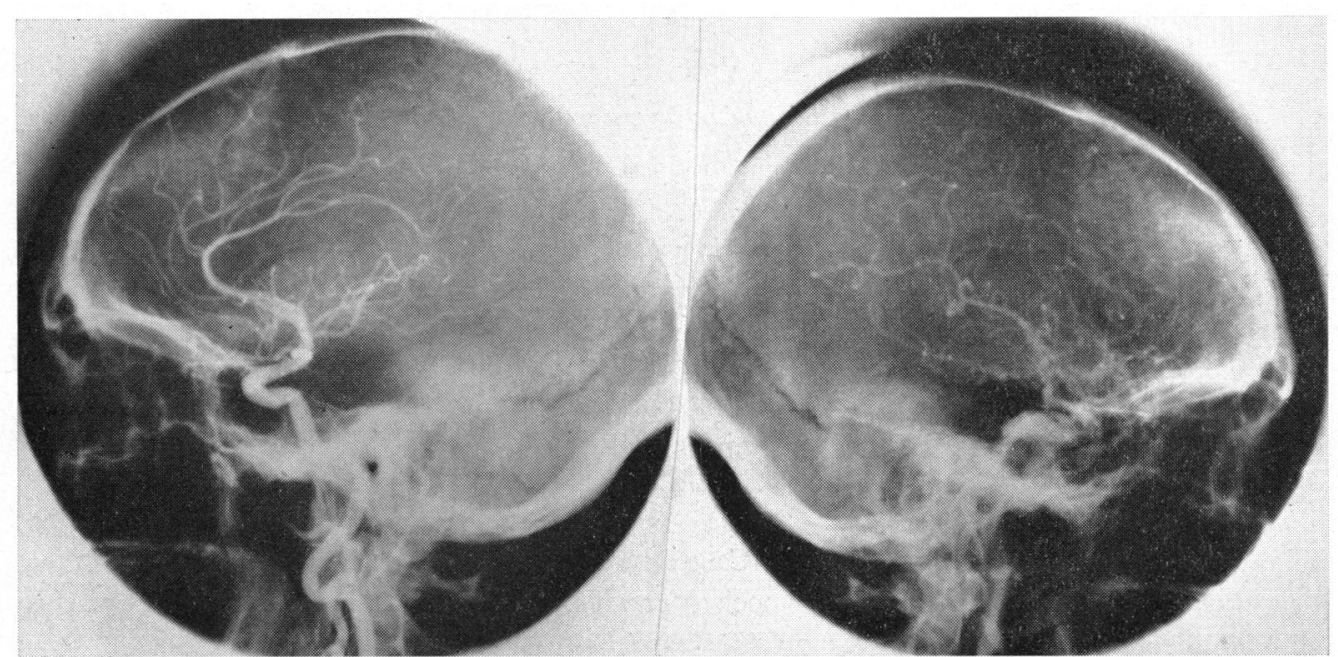

FIG. 2.-Normal left carotid angiogram.

FIG. 3.-Arterio-venous shunt in cavernous sinus seen in right carotid angiogram.

Carotid compression was tried, but because of a tender scar in her neck (site of an old tubercular gland operation) could not be efficiently carried out at the time. A few weeks later, however, she permitted firm right carotid compression and it was found that this abolished the bruit.

Treatment.-She was very averse to any form of surgery and was therefore followed up as an out-patient, and given pilocarpine 2 per cent. drops four times a day to the left eye.

Progress.-In January, 1963, the symptoms were unchanged but the eye signs had altered. She now showed right (!) abduction paresis with full movements of the left eye. This was confirmed on the Hess chart. The left proptosis was slightly less, and the conjunctival chemosis had disappeared.

Despite pilocarpine drops the left intra-ocular pressure remained above normal (Fig. 4), and in June, 1963, she agreed to have surgical treatment.

Operations.-The right common carotid artery was occluded by a temporary clip. As no illeffects were noticed after half an hour and the bruit was abolished, the artery was doubly ligated and divided. The patient made an uneventful recovery.

Post-operatively the right external rectus paresis persisted but the bruit did not return. No drops were necessary in the left eye. The intra-ocular pressure has remained at or below $21 \mathrm{~mm}$. $\mathrm{Hg}$ in this eye (Fig. 4, opposite).

In November, 1963, resection of the right external rectus $5 \mathrm{~mm}$. and recession of the right internal rectus $3 \mathrm{~mm}$. was performed.

Result.-Since this operation she has remained symptom-free, with no diplopia, and visual acuity right and left $6 / 6$ unaided. Intra-ocular pressure right -18 and left $-21 \mathrm{~mm}$. $\mathrm{Hg}$. Central visual fields full to 2/2000 white. She is still under observation. 


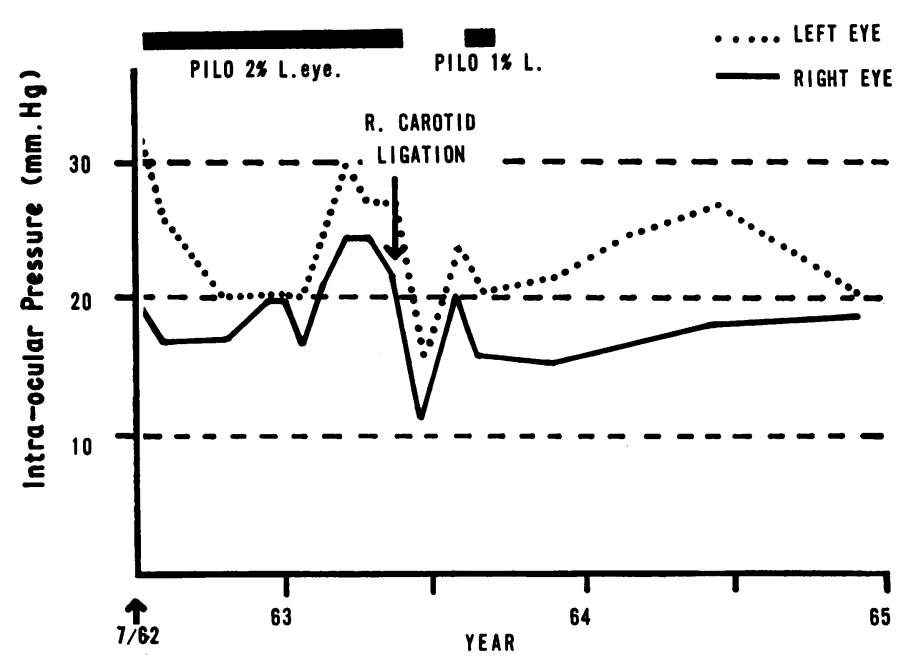

FIG. 4.-Intra-ocular pressure before and after right carotid ligation.

\section{Discussion}

A feature of this case was the initial absence of signs on the side of the lesion, apart from the bruit which was best heard over the right eye. This latter proved the best localizing sign. Because of tenderness in the neck, carotid compression could not at first be tolerated, but at a later date this provided confirmatory evidence as to the side of the lesion.

A few cases of arterio-venous shunt in the cavernous sinus are on record with chiefly contralateral signs. That of Dandy (1941) came to necropsy, and he found no communication between the involved cavernous sinus and the ipsilateral orbit, because of a thrombus at the ophthalmic vein entrance. An excellent communication via the intercavernous sinuses enabled the increased pressure to be transmitted to the contralateral sinus and orbit via the intact ophthalmic veins on the other side. A similar explanation may well account for the findings in the present case, the eye contralateral to the vascular lesion being the only one which showed pulsation, proptosis, and secondary glaucoma.

The contralateral abduction paresis is not so easily explained. One theory put forward by Dandy was enlargement of the cavernous sinus with consequent stretching of the nerve. In his case there was also a pouch projection of the sinus which pressed against the third nerve, compressing and stretching it. I would suggest that the stretching may also be increased by lateral displacement of the carotid artery in an enlarged sinus. Recovery of the sixth nerve, or its blood supply, apparently occurred in the present case, but the ipsilateral nerve seems to have been similarly affected at a later stage. Presumably the lesion involving the nerve was in the cavernous sinus itself on the ipsilateral side. Again, carotid arterial displacement or pressure of an arterial thrombus might be contributing factors.

The good response of the raised intra-ocular pressure in the left eye to carotid ligation has been particularly gratifying. Although the left intra-ocular pressure is within normal limits, it is still $3 \mathrm{~mm}$. higher than in the right eye, probably because 
of some persistence of unilateral raised intra-orbital venous pressure. This supports the view that either a thrombosis of the right superior ophthalmic vein occurred, or the venous drainage of the right orbit was directed to the pterygoid plexus without any communication with the cavernous sinus. This would account for the absence of proptosis of the right eye. As this patient is still under observation it will be interesting to see whether the intra-ocular pressure in the left eye later shows signs of rising, indicating a possible resurgence of pressure from a developing collateral circulation.

This case illustrates the need for bilateral angiography in any case of suspected arterio-venous fistula in the cavernous sinus to exclude a bilateral lesion or aneurysm.

In previous cases, visual loss has frequently been reported but without many details. Short-term visual loss could be due to pressure on the optic nerve by the carotid artery displaced by a distended cavernous sinus. Cases with more gradual visual loss are probably due to uncontrolled secondary glaucoma.

\section{Summary}

A case of right arterio-venous communication in the cavernous sinus is presented. Initially most of the signs were contralateral to the lesion.

Theories are advanced to account for these findings.

My thanks are due to Mr. Charles Langmaid and Mr. R. A. C. Jones, who performed the carotid ligation, and to Mr. Ralph Marshall, of the Department of Medical Illustration, Cardiff Royal Infirmary, who provided the illustrations.

\section{REFERENCES}

DANDY, W. E., and Follis, R. H. (1941). Amer. J. Ophthal., 24, 365.

HAMBY, W. B. (1952). "Intracranial Aneurysms". Thomas, Springfield, Ill.

JefFERSON, G. (1950). "Intracranial Aneurysms". Balfour Lecture, University of Toronto.

RAMOs, M., and Mount, L. A. (1953). J. Neurosurg., 10, 178.

WALSH, F. B. (1957). "Clinical Neuro-ophthalmology", 2nd ed., pp. 850-61. Williams and Wilkins, Baltimore. 